\title{
Optimization of osteoporosis and osteopenia management among renal transplant recipients
}

\author{
Mohammed K. Afifi ${ }^{1}$, Ahmed S. Kenawy' ${ }^{1}$, Heba H. El Demellawy ${ }^{2}$, Amany A. Azouz ${ }^{3}$, Torki Al-Otaibi', \\ Osama Gheith", ${ }^{1,4}$ Mohamed Abd ElMonem', Mohamed S. AbdElhalim and Raghda R. S. Hussein 5,6* (D)
}

\begin{abstract}
Background: Osteoporosis and osteopenia occur frequently in renal transplant recipients due to long-term use of immune-suppressants including corticosteroids. Previous treatment options like bisphosphonates had acceptable but rather unsatisfactory results after transplant. The aim of the current study is to directly compare the efficacy of denosumab and oral ibandronate in late RTR with low bone mineral density.

Results: The study was conducted lin Hamed Al-Essa Kidney transplant center, Kuwait, in 2020. The data of 52 denosumab and 48 ibandronate patients were collected at the baseline and after one year of treatment. Spine and hip T-score readings, side effects, and other laboratory results were analyzed to evaluate the use of both medications. The mean number of months after transplant was 25 ( \pm 13.9) months. After one year of treatment, denosumab alleviated both spinal osteoporosis and osteopenia T-score values from -3.13 to $-2.4(p=0.008)$ and from -1.9 to $-1.5(p=0.015)$, respectively. Besides, it reduced hip osteoporosis and osteopenia insignificantly from -3.45 to -3.1 and from -1.5 to -1.3 , respectively $(p>0.05)$. Ibandronate improved spinal osteopenia from -1.6 to $-1.55(p=0.97)$ and failed to show any positive impact on other sites; the spinal osteoporosis changed from -2.8 to -3 and hip osteoporosis and osteopenia changed from -3.1 to -3.12 and from -1.4 to -1.45 , respectively $(p>0.05)$. The use of ibandronate was more associated with gastrointestinal tract (GIT) side effects, while hypocalcemia episodes were significantly higher in the denosumab group.
\end{abstract}

Conclusion: Denosumab improved both spinal and hip T-score values in comparison with ibandronate in RTR. Close monitoring is required for denosumab patients to prevent the associated hypocalcemia.

Keywords: Denosumab, Ibandronate, Transplant, Osteoporosis, Osteopenia

\footnotetext{
${ }^{*}$ Correspondence: raghda.hussien@pharm.bsu.edu.eg

${ }^{5}$ Department of Clinical Pharmacy, Faculty of Pharmacy, Beni-Suef

University, Beni-Suef 62514, Egypt

Full list of author information is available at the end of the article
} 


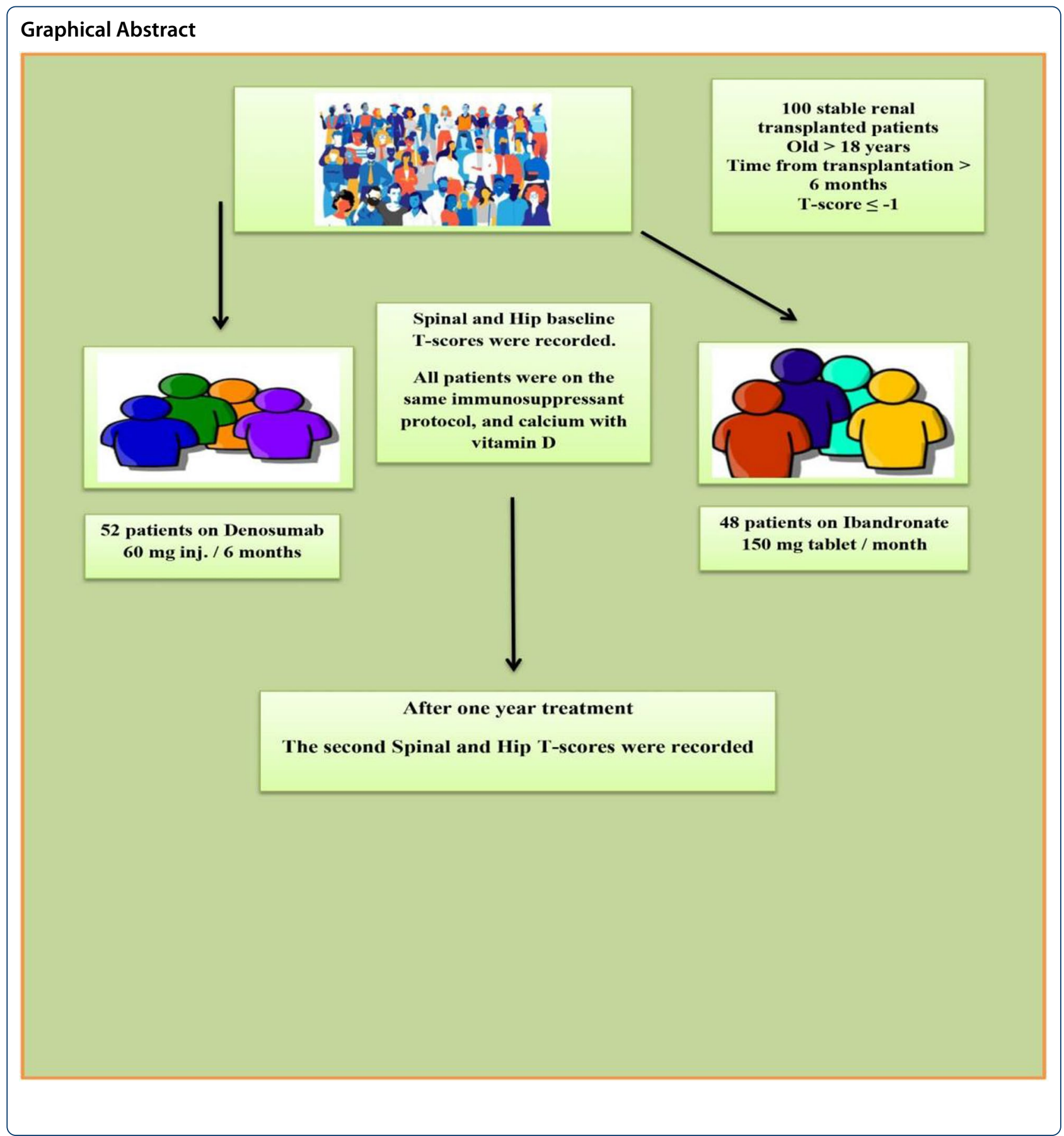

\section{Background}

Bone diseases in renal transplant recipients (RTR) are characterized by bone volume loss and mineralization problems that lead to low turnover bone disease, like osteopenia and osteoporosis, in the majority of these patients. The main contributing factors for this problem are: preexisting renal osteodystrophy at the time of renal transplantation, transplantation-specific therapies (tacrolimus, mycophenolate, and steroids), reduced renal function, and hyperparathyroidism [1-6]. Pharmacological treatments include correction of mineral metabolism disorders using calcium and vitamin D supplements, and antiresorptive drugs like bisphosphonate, denosumab, and estrogen receptor modulators $[7,8]$. 
Denosumab is a 6 monthly injection that inhibits RANKL (receptor activator of nuclear factor-kappa-B ligand) from activating its receptor on the osteoclast surface, therefore restrains the formation and differentiation of osteoclasts and decreases bone resorption [9]. The bioavailability of denosumab is $61 \%$ and its maximum serum concentration is achieved in 5-21 days and can be detected in blood for 9 months or longer. Denosumab is presumably cleared by the reticuloendothelial system with minimal renal filtration and excretion. The elimination half-life is 32 days and the terminal half-life is $5-10$ days [10].

The bisphosphonate (ibandronate) improves bone mineral density (BMD) by decreasing osteoclast activities and reducing bone resorption [11]. It is effective in treating corticosteroid-induced osteoporosis and has rapid oral absorption (T-max $<1 \mathrm{~h}$ ), and low bioavailability $(0.63 \%)$ that is strongly affected by food. Ibandronate is reserved in bones and eliminated from blood by both bone mass (40$50 \%)$ and kidney $[12,13]$. The adverse effects of bisphosphonate include adynamic bone disease, glomerular injury, jaw necrosis, and esophageal irritation [14-19].

Previous researches have studied the effect of both ibandronate and denosumab in renal patients. Smerud et al. showed that ibandronate had a limited effect in preventing lumbar spine bone loss in 129 renal transplant patients but had a favorable effect in total femur [20]. Another study by Brunova et al. indicated that the traditional osteoporosis therapies including bisphosphonates had a limited effect on transplanted patients with impaired renal functions, while denosumab had an advantage over them by decreasing the spinal osteoporosis prevalence from 75 to $27 \%$ [21]. A third study was performed on 90 de novo kidney transplant recipients by Bonani et al., this study concluded that denosumab had significantly improved BMD at the lumbar spine by $5.1 \%$ and at total hip by $1.9 \%$ in the first year after kidney transplantation [20-22].

Previous studies focused on comparing the effect of densumab and bisphosphonates (like intravenous ibandronate) on de novo kidney transplant patients or evaluating it alone in RTR, on the other hand, this study aimed to directly compare the efficacy of denosumab and oral ibandronate in late RTR with low BMD. Oral ibandronate is the only bisphosphonate available to use in Hamed Al-Essa Kidney transplant center in Kuwait.

\section{Methods}

\section{Ethical approval}

The ethical committee in the Kuwaiti Ministry of Health approved the study protocol with a Registration No. $2017 / 620$.

\section{Study design}

This retrospective study was carried out in the outpatient department of Hamed Al-Essa Organ Transplant Centre (OTC) in Kuwait. The participants were considered eligible if they were 18-year-old or above, six months or more after transplant, had a stable renal function with T-score $\leq-1$, and could read and sign the informed consent. The medications' compliance for each patient was assessed using the pharmacy registration program. This program provided information about the regularity of medication dispensing from the pharmacy.

All RTR were receiving immunosuppressive medications (glucocorticoids and calcineurin-inhibitors) with normal renal function. The patients were treated for osteoporosis and osteopenia with calcium and vitamin $\mathrm{D}$ and either ibandronate $150 \mathrm{mg}$ tablets once per month or denosumab $60 \mathrm{mg}$ every 6 months. Two T-score readings were collected, one reading before treatment and the second one after one year of treatment. The T-score readings were compared between the studied groups. The T-score for osteopenia is between -1.0 and -2.4 , and -2.5 or below for osteoporosis.

The demographic data (age, sex, and immune-suppressant drugs), clinical reports, and laboratory values were collected from the patient files. The patients regularly visited the OTC every 3 months for routine checks. BMD expressed by $\mathrm{T}$-score was determined at baseline and after one year of the medication use. The levels of creatinine, calcium, phosphorus, and other parameters (vitamin D, urea, sodium, chloride, and uric acid) were collected for the study period and the mean was calculated to compare the groups.

Statistical analysis was conducted using SPSS version 26 (Chicago, IL, USA). Data were normally distributed, and hence, values of continuous variables were expressed as means. Independent student T-test was used to compare the studied groups. Categorical data were presented as a percentage and compared using the Chi-square test. Statistical significance was set at $P<0.05$. Sample size was determined using the formulas for two independent study groups with continuous variable, $\alpha=0.05$, and study power $=80 \%$.

\section{Results}

The results of 100 kidney transplant recipients (52 denosumab patients and 48 ibandronate patients) were included in the study. No significant differences were detected between the groups in the baseline T-scores, gender, age, or other parameters. The baseline characteristics of the participants are presented in Table 1. 
Table 1 Baseline characteristics of the participants

\begin{tabular}{|c|c|c|c|}
\hline Parameter (reference) & $\begin{array}{l}\text { Denosumab } \\
(n=52)\end{array}$ & $\begin{array}{l}\text { Ibandronate } \\
(n=48)\end{array}$ & $P$ value \\
\hline Gender (male/female) & $24 / 28$ & $21 / 27$ & $0.80^{\mathrm{a}}$ \\
\hline Age & $56.08( \pm 14)$ & $53.32( \pm 13)$ & $0.54^{\mathrm{a}}$ \\
\hline $\begin{array}{l}\text { Osteopenia/ Osteoporosis } \\
\text { patients }\end{array}$ & $40 / 12$ & $37 / 11$ & $0.98^{\mathrm{a}}$ \\
\hline $\begin{array}{l}\text { Time after Transplant } \\
\text { (months) }\end{array}$ & $24.9( \pm 13.85)$ & $25.46( \pm 14.18)$ & $0.84^{\mathrm{a}}$ \\
\hline Body Mass Index (kg/m²) & $29.9( \pm 5.2)$ & $29.6( \pm 4.6)$ & $0.71^{\mathrm{a}}$ \\
\hline Vitamin D (75-250 nmol/L) & $63.52( \pm 8.1)$ & $55.07( \pm 9.7)$ & $0.15^{\mathrm{a}}$ \\
\hline Calcium (2.2-2.5 mmol/L) & $2.33( \pm 0.17)$ & $2.35( \pm 14)$ & $0.19^{\mathrm{a}}$ \\
\hline $\begin{array}{l}\text { Phosphorous (0.8- } \\
1.5 \mathrm{mmol} / \mathrm{L})\end{array}$ & $1.18( \pm 0.15)$ & $1.17( \pm 0.26)$ & $0.69^{\mathrm{a}}$ \\
\hline $\begin{array}{l}\text { Serum creatinine (40- } \\
115 \mu \mathrm{mol} / \mathrm{L})\end{array}$ & $105.4( \pm 29.45)$ & $109.6( \pm 28.68)$ & $0.07^{\mathrm{a}}$ \\
\hline Urea (2.5-6.4 mmol/L) & $5.95( \pm 2.5)$ & $5.35( \pm 2.89)$ & $0.32^{\mathrm{a}}$ \\
\hline Sodium (135-145 mmol/L) & $138.25( \pm 3.23)$ & $138.82( \pm 4.07)$ & $0.77^{\mathrm{a}}$ \\
\hline Chloride (98-107 mmol/L) & $103.86( \pm 2.95)$ & $103.2( \pm 3.63)$ & $0.88^{\mathrm{a}}$ \\
\hline Uric acid (208-425 بmol/L) & $364.75( \pm 79)$ & $372.69( \pm 65)$ & $0.17^{\mathrm{a}}$ \\
\hline Total Cumulative Steroid (gm) & $1.58( \pm 0.25)$ & $1.51( \pm 0.30)$ & $0.48^{\mathrm{a}}$ \\
\hline \multicolumn{4}{|l|}{ T-score } \\
\hline Spinal Osteoporosis & $-3.13( \pm 0.6)$ & $-2.80( \pm 0.3)$ & $0.26^{\mathrm{a}}$ \\
\hline Spinal Osteopenia & $-1.9( \pm 0.27)$ & $-1.6( \pm 0.15)$ & $0.44^{\mathrm{a}}$ \\
\hline Hip Osteoporosis & $-3.45( \pm 0.4)$ & $-3.1( \pm 0.6)$ & $0.94^{\mathrm{a}}$ \\
\hline Hip Osteopenia & $-1.5( \pm 0.2)$ & $-1.4( \pm 0.23)$ & $0.94^{\mathrm{a}}$ \\
\hline \multicolumn{4}{|l|}{ Immunosuppression } \\
\hline Predinsolone & $52(100 \%)$ & $48(100 \%)$ & - \\
\hline Mycophenolate & $52(100 \%)$ & 48 (100\%) & - \\
\hline Tacrolimus & $42(80 \%)$ & $36(75 \%)$ & \\
\hline Cyclosporine & $10(20 \%)$ & $12(25 \%)$ & $0.49^{\mathrm{a}}$ \\
\hline
\end{tabular}

Data are presented at baseline as number only, mean \pm standard deviation, or percentages only

Categorical data are presented as percentages and were compared using the chi-squared test, while the Student T-test was used for normally distributed variables; significance was found at $P \leq 0.05$

${ }^{a}$ Nonsignificant difference between the two groups

After one year of treatment, No significant differences were detected in creatinine levels, calcium, or other minerals after using both denosumab and ibandronate $(P>0.05)$. Ibandronate patients reported more side effects related to the gastrointestinal tract (GIT) than the other group, while denosumab patients had more hypocalcemia episodes as shown in Table 2.

After one year of treatment, the spinal osteoporosis and osteopenia $\mathrm{T}$-score values improved significantly from -3.13 to -2.4 and from -1.9 to -1.5 in the denosumab group, respectively. We observed only a mild insignificant improvement in spinal osteopenia T-score value (from -1.6 to -1.55 ) in the ibandronate group. In spinal osteoporosis, denosumab increased T-score over that in the ibandronate group by $23 \%(p=0.041)$,
Table 2 The average levels of the participants characteristics after one year of treatment

\begin{tabular}{|c|c|c|c|}
\hline Parameter (reference) & $\begin{array}{l}\text { Denosumab } \\
(n=52)\end{array}$ & $\begin{array}{l}\text { lbandronate } \\
(n=48)\end{array}$ & $P$-value \\
\hline Vitamin D (75-250 nmol/L) & $62.2( \pm 6.2)$ & $56( \pm 7.1)$ & $0.15^{\mathrm{a}}$ \\
\hline Calcium (2.2-2.5 mmol/L) & $2.30( \pm 0.15)$ & $2.33( \pm 0.16)$ & $0.67^{\mathrm{a}}$ \\
\hline Phosphorous (0.8-1.5 mmol/L) & $1.19( \pm 0.14)$ & $1.17( \pm 0.19)$ & $0.69^{\mathrm{a}}$ \\
\hline $\begin{array}{l}\text { Serum creatinine (40- } \\
115 \mu \mathrm{mol} / \mathrm{L})\end{array}$ & $107.3( \pm 25.5)$ & $109.2( \pm 26.3)$ & $0.68^{\mathrm{a}}$ \\
\hline Urea $(2.5-6.4 \mathrm{mmol} / \mathrm{L})$ & $6.1( \pm 2.3)$ & $5.55( \pm 2.62)$ & $0.18^{\mathrm{a}}$ \\
\hline Sodium (135-145 mmol/L) & $138.52( \pm 3.4)$ & $138.7( \pm 3.9)$ & $0.69^{\mathrm{a}}$ \\
\hline Chloride $(98-107 \mathrm{mmol} / \mathrm{L})$ & $103.5( \pm 3.1)$ & $103.6( \pm 3.31)$ & $0.79^{\mathrm{a}}$ \\
\hline Uric acid (208-425 $\mu \mathrm{mol} / \mathrm{L})$ & $343.81( \pm 75)$ & $351.68( \pm 69)$ & $0.31^{\mathrm{a}}$ \\
\hline \multicolumn{4}{|l|}{ Reported side effects } \\
\hline Injection site reaction & $10(20 \%)$ & 0 & - \\
\hline Stomach upset & 0 & $11(22.9 \%)$ & $0.001^{b}$ \\
\hline Abdominal pain & $8(15.4 \%)$ & $9(18.75 \%)$ & $0.65^{\mathrm{a}}$ \\
\hline Diarrhea and vomiting & $5(9.6 \%)$ & $15(31.25 \%)$ & $0.006^{b}$ \\
\hline Hypocalcaemia & $6(11.5 \%)$ & $1(2.1 \%)$ & $0.037^{b}$ \\
\hline Fractures & 0 & 0 & - \\
\hline Acute rejection & 0 & 0 & - \\
\hline
\end{tabular}

Data are presented after one year of treatment as number only, mean \pm standard deviation, or percentages only

Categorical data are presented as percentages and were compared using the chi-squared test, while the Student T-test was used for normally distributed variables; significance was found at $P \leq 0.05$

${ }^{a}$ Nonsignificant difference between the two groups. ${ }^{b}$ Significant difference between the two groups

while in spinal osteopenia, T-score improved by $21 \%$ $(p=0.033)$ as illustrated in Table 3 and Fig. 1.

The hip osteoporosis and osteopenia T-score values improved in denosumab group (from 3.45 to -3.1 and from -1.5 to -1.3 , respectively) and decreased in ibandronate group (from -3.1 to -3.12 and from -1.4 to -1.45 , respectively), the $\mathrm{T}$-score change in both groups was insignificant. No significant difference was

Table 3 Spinal T-scores at baseline and after one year of treatment

\begin{tabular}{|c|c|c|c|c|}
\hline & Baseline & After 1 year & Net change & $P$ value \\
\hline \multicolumn{5}{|c|}{ Spinal Osteoporosis } \\
\hline Denosumab & $-3.13( \pm 0.6)$ & $-2.4( \pm 0.41)$ & 0.73 & $0.008^{\mathrm{b}}$ \\
\hline Ibandronate & $-2.8( \pm 0.3)$ & $-3( \pm 0.37)$ & -0.2 & $0.178^{\mathrm{a}}$ \\
\hline \multicolumn{5}{|c|}{ Spinal Osteopenia } \\
\hline Denosumab & $-1.9( \pm 0.27)$ & $-1.5( \pm 0.32)$ & 0.4 & $0.015^{b}$ \\
\hline Ibandronate & $-1.6( \pm 0.15)$ & $-1.55( \pm 0.5)$ & 0.05 & $0.97^{\mathrm{a}}$ \\
\hline
\end{tabular}

The Student T-test was used for normally distributed variables; significance was found at $P \leq 0.05$

${ }^{a}$ Nonsignificant difference between the two groups. ${ }^{b}$ Significant difference between the two groups 


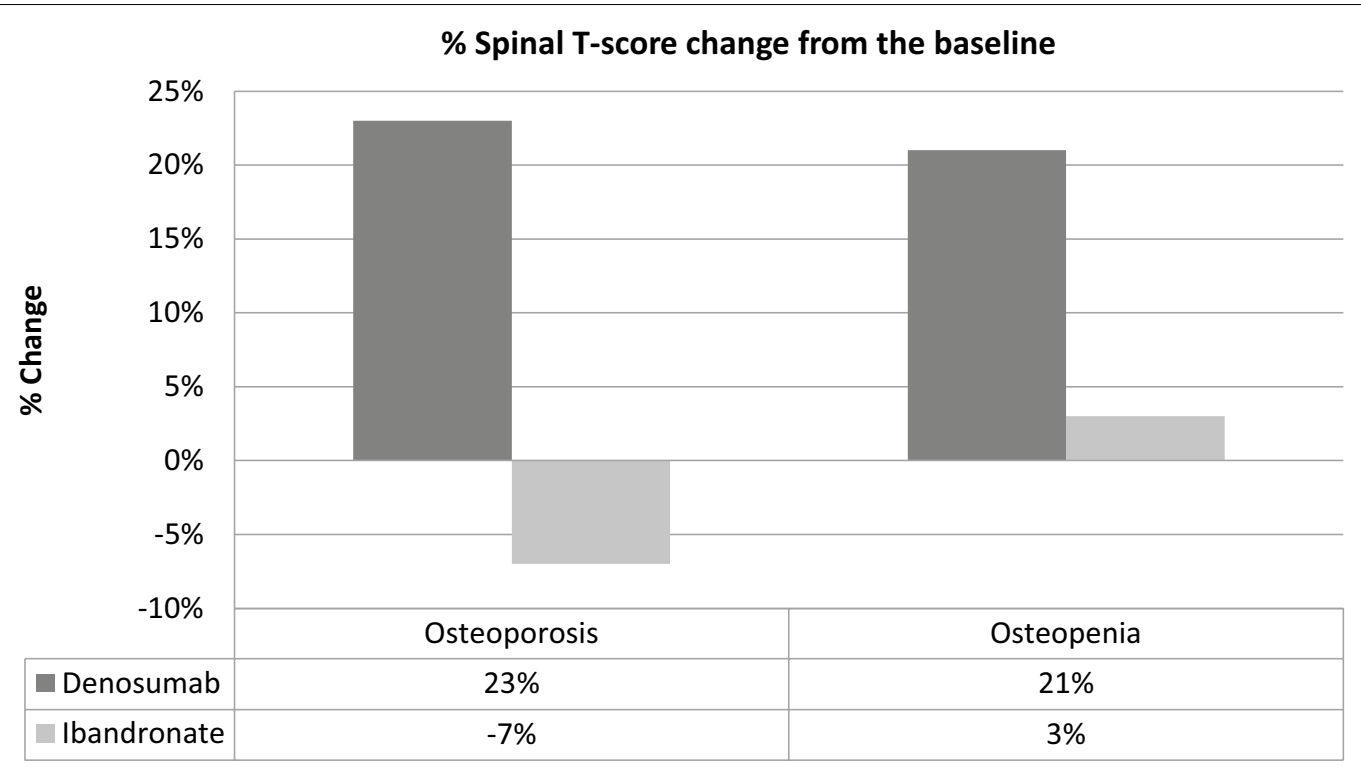

The data shows the percentage change in the spinal T-score from the baseline after one year of treatment,

Fig. 1 Percentage Spinal T-score change from the baseline

Table 4 Hip T-scores at baseline and after one year of treatment

\begin{tabular}{ccccc}
\hline \multicolumn{1}{c}{ Baseline } & After 1 year & Net change & $P$ value \\
\hline Hip Osteoporosis & & & & \\
Denosumab & $-3.45( \pm 0.4)$ & $-3.1( \pm 0.5)$ & 0.35 & $0.34^{\mathrm{a}}$ \\
Ibandronate & $-3.1( \pm 0.6)$ & $-3.12( \pm 0.52)$ & -0.02 & $0.91^{\mathrm{a}}$ \\
Hip Osteopenia & & & & \\
Denosumab & $-1.5( \pm 0.2)$ & $-1.3( \pm 0.42)$ & 0.2 & $0.12^{\mathrm{a}}$ \\
Ibandronate & $-1.4( \pm 0.23)$ & $-1.45( \pm 0.46)$ & -0.05 & $0.81^{\mathrm{a}}$ \\
\hline
\end{tabular}

The Student T-test was used for normally distributed variables; significance was found at $P \leq 0.05$

${ }^{\text {a }}$ Nonsignificant difference between the two groups

detected in the percentage of hip T-score change from baseline between the two groups $(p>0.05)$ as indicated in Table 4 and Fig. 2.

\section{Discussion}

Bone diseases are considered a serious problem in Kuwait; the proportion of osteoporosis among the Kuwaiti population is relatively high if compared to international standards [23]. This problem is more apparent in RTR because of transplant complications and medications used before and after transplantation. In Hamed Al-Essa organ transplant center, more than $40 \%$ of the patients suffer from osteoporosis or osteopenia, those patients need frequent follow-up to prevent any complications associated with these conditions. Twenty percent of transplant patients develop a fracture in the first
5 years after transplant [24]. For that, it is important to use safe and effective medications to treat the underlined problem and protect the transplanted organ.

After one year of treatment, denosumab improved both spinal and hip T-score values in comparison with ibandronate, this result is consistent with previous studies that have demonstrated the preferable effect of denosumab over bisphosphonate in RTR. Mckee et al. showed a greater increase in both spinal and femoral neck BMD $\left(0.045\right.$ and $0.022 \mathrm{~g} / \mathrm{cm}^{2}$, respectively) in denosumab group over the bisphosphonate group after almost 3 years of follow-up in RTR [28]. Besides, denosumab improved both spinal and hip T-score values significantly by 0.42 and 0.1, respectively, in the study performed by Bonani et al. [22]. Besides, Tillmann et al. did not detect a significant improvement in BMD after using ibandronate in RTR as compared to the control group [22, 25, 26].

Bisphosphonates, calcium, and vitamin D have been previously proved to decrease the rate of bone loss after transplant, the same combination failed to increase the bone mass at all sites in RTR [8, 20, 27, 28]. In contrast to ibandronate that decreases osteoclast activity, denosumab acts mainly by inhibiting RANKL system. This unique mode of action is specifically useful in RTR because of the activation of the RANKL system by glucocorticoids and calcineurin inhibitors, which may explain the ability of denosumab to increase bone mass in RTR who use these medications in high doses after transplant [29]. At the same time, the 6 monthly use of denosumab injection is a less troublesome option for RTR who use 


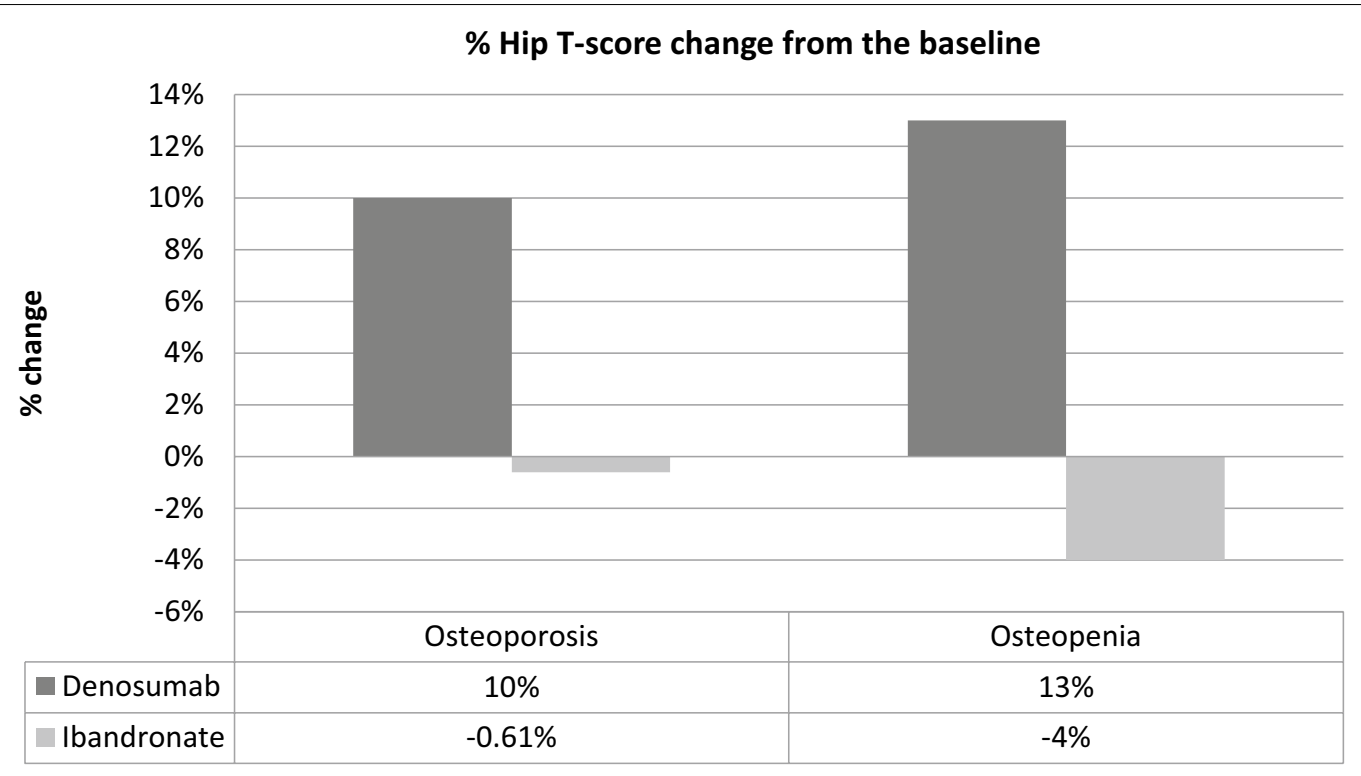

The data shows the percentage change in the hip T-score from the baseline after one year of treatment

Fig. 2 Percentage hip T-score change from the baseline

a lot of medications to prevent rejection of the transplanted organ or treat other conditions like hypertension and diabetes [30].

The use of ibandronate in this study was more associated with GIT side effects like stomach upset and vomiting, which is a well-known bothersome effect of using oral bisphosphonates in general [31]. Although its use was more tolerable, the reported hypocalcemia episodes were significantly higher with denosumab. These episodes were not severe and did not need any interventions except increasing the oral calcium dose. Close monitoring of calcium levels is likely needed with stage 4 and 5 chronic kidney disease and new denosumab patients because they are more susceptible to be affected with hypocalcemia [32].

The encouraging results of denosumab in RT patients may give the nephrologists a reliable option to be used safely and effectively after, or even directly after, transplantation. Bonanai et al. used denosumab in de novo kidney transplant patients with the auspicious results, as it increased areal bone mineral density (aBMD) at all sites, improved cortical volumetric bone mineral density (vBMD), and decreased blood and urine bone turnover biomarkers significantly [22]. Other medications used for osteoporosis like ibandronate failed to demonstrate such results. In addition, ibandronate is not recommended in patients with CrCL less than $30 \mathrm{ml} / \mathrm{min}$ [33].

The study has some limitations like the inability to assess bone turnover biomarkers like $\beta$-CTX and urine deoxypyridinoline. Also, the assessment period (1 year) was not long enough to evaluate long term efficacy and safety.

\section{Conclusions}

In one-year follow-up, denosumab presented an effective choice to manage osteoporosis and osteopenia in renal transplant recipients, as it significantly improved T-score values more effectively than ibandronate. Calcium levels should be monitored after using denosumab to prevent the hypocalcemia associated with its use.

\section{Abbreviations}

RTR: Renal transplant recipients; RANKL: Receptor activator of nuclear factorkappa-B ligand; BMD: Bone mineral density; OTC: Organ Transplant Centre; GIT: Gastrointestinal tract; aBMD: Areal bone mineral density; vBMD: Volumetric bone mineral density.

\section{Acknowledgements}

The authors are truly grateful to Dr. Prasad Nair, Dr.Tarek Said, Dr. Medhat Abdel Halim, Dr. Khaled Abdel Tawab, Dr. Ayman Naguib, Ms. Najat Al-Ali, and the nursing staff at the Hamed Al-Essa Center for Organ Transplantation for their support and help during this research.

\section{Authors' contributions}

M.K.A, A.S.K, M.S.A contributed to study design, conception, data collection, data entry, analysis, and writing.. A. A. A and R. R. S. H study design, data entry, and drafting the manuscript.. H. H. E contributed to study design, data entry, provided intellectual content of critical importance to the work and technical support and drafting the manuscript. O.G contributed to study design and data entry. T. A: provided intellectual content of critical importance to the work and technical support and drafting the manuscript. M.A.E contributed to study design, provided intellectual content of critical importance to the 
work and technical support and drafting the manuscript. All authors read and approved the final manuscript.

\section{Funding}

None.

\section{Availability of data and materials}

The datasets used and/or analysed during the current study are available from the corresponding author on reasonable request.

\section{Declarations}

\section{Ethics approval and consent to participate}

Ethics'approval was obtained from the Kuwaiti Ministry of Health. The consent to participate was verbal and the reason is the available system at ibn Sinai Hospital, besides this study is a retrospective study getting the ethical approval from the Kuwaiti Ministry of Health to get the data (the ethical approval was attached as supplementary data).

\section{Consent for publication}

Not applicable.

\section{Competing interests}

The authors declare that they have no competing interests.

\section{Author details}

${ }^{1}$ Hamed Al-Essa Organ Transplant Center, Ibn Sina Hospital, Al-Shuwaikh, Kuwait. ${ }^{2}$ Department of Nephrology, Faculty of Medicine, Beni-Suef University, Beni-Suef, Egypt. ${ }^{3}$ Department of Pharmacology and Toxicology, Faculty of Pharmacy, Beni-Suef University, Beni-Suef, Egypt. ${ }^{4}$ Urology and Nephrology Center, Mansoura University, Mansoura, Egypt. ${ }^{5}$ Department of Clinical Pharmacy, Faculty of Pharmacy, Beni-Suef University, Beni-Suef 62514, Egypt. ${ }^{6}$ Department of Clinical Pharmacy, Faculty of Pharmacy, Modern University for Technology and Information, Cairo, Egypt.

Received: 25 August 2021 Accepted: 13 November 2021

Published online: 27 November 2021

\section{References}

1. Molnar MZ et al (2014) Bone and mineral disorders after kidney transplantation: therapeutic strategies. Transpl Rev 28(2):56-62

2. Vautour LM et al (2004) Long-term fracture risk following renal transplantation: a population-based study. Osteoporos Int 15(2):160-167

3. Cunningham J (2005) Posttransplantation bone disease. Transplantation 79(6):629-634

4. Epstein S (1996) Post-transplantation bone disease: the role of immunosuppressive agents and the skeleton. J Bone Miner Res 11(1):1-7

5. Wolf M et al (2016) A prospective cohort study of mineral metabolism after kidney transplantation. Transplantation 100(1):184

6. Weisinger JR et al (2006) Bone disease after renal transplantation. Clin J Am Soc Nephrol 1(6):1300-1313

7. Arnold R et al (2016) Neurological complications in chronic kidney disease. JRSM Cardiovasc Dis 5:2048004016677687

8. De Sévaux RG et al (2002) Treatment with vitamin D and calcium reduces bone loss after renal transplantation: a randomized study. J Am Soc Nephrol 13(6):1608-1614

9. Narayanan P (2013) Denosumab: a comprehensive review. South Asian journal of cancer 2(4):272

10. Lewiecki EM (2006) RANK ligand inhibition with denosumab for the management of osteoporosis. Expert Opin Biol Ther 6(10):1041-1050
11. Wang J et al (2016) Bisphosphonates for prevention of osteopenia in kidney-transplant recipients: a systematic review of randomized controlled trials. Osteoporos Int 27(5):1683-1690

12. Barrett J et al (2004) Ibandronate: a clinical pharmacological and pharmacokinetic update. J Clin Pharmacol 44(9):951-965

13. Frampton JE, Perry CM (2008) Ibandronate. Drugs 68(18):2683-2707

14. Coco M et al (2003) Prevention of bone loss in renal transplant recipients: a prospective, randomized trial of intravenous pamidronate. J Am Soc Nephrol 14(10):2669-2676

15. Pascual J et al (2007) Collapsing focal segmental glomerulosclerosis in a liver transplant recipient on alendronate. Osteoporos Int 18(10):1435-1438

16. Munier A et al (2005) Zoledronic acid and renal toxicity: data from French adverse effect reporting database. Ann Pharmacother 39(7-8):1194-1197

17. Bilezikian JP (2006) Osteonecrosis of the jaw-do bisphosphonates pose a risk? N Engl J Med 355(22):2278

18. Graham DY (2002) What the gastroenterologist should know about the gastrointestinal safety profiles of bisphosphonates. Dig Dis Sci 47(8):1665-1678

19. Strampel W, Emkey R, Civitelli R (2007) Safety considerations with bisphosphonates for the treatment of osteoporosis. Drug Saf 30(9):755-763

20. Smerud K et al (2012) A 1-year randomized, double-blind, placebocontrolled study of intravenous ibandronate on bone loss following renal transplantation. Am J Transplant 12(12):3316-3325

21. Brunova J, Kratochvilova S, Stepankova J (2018) Osteoporosis therapy with denosumab in organ transplant recipients. Front Endocrinol 9:162

22. Bonani $\mathrm{M}$ et al (2016) Effect of twice-yearly denosumab on prevention of bone mineral density loss in de novo kidney transplant recipients: a randomized controlled trial. Am J Transpl 16(6):1882-1891

23. Al-Shoumer KA, Nair V (2012) Prevalence of low bone mass in postmenopausal Kuwaiti women residents in the largest province of Kuwait. Arch Osteoporos 7(1):147-153

24. Nikkel LE et al (2009) Risk of fractures after renal transplantation in the United States. Transplantation 87(12):1846-1851

25. Tillmann F et al (2016) Ibandronate in stable renal transplant recipients with low bone mineral density on long-term follow-up. Int Urol Nephrol 48(2):279-286

26. McKee $\mathrm{H}$ et al (2020) Comparison of the clinical effectiveness and safety between the use of denosumab vs bisphosphonates in renal transplant patients. Osteoporos Int 31(5):973-980

27. Stein EM et al (2011) Prevention of fractures after solid organ transplantation: a meta-analysis. J Clin Endocrinol Metab 96(11):3457-3465

28. Palmer SC et al (2019) Interventions for preventing bone disease in kidney transplant recipients. Cochrane Database Syst Rev 2019(10)

29. Early C, Stuckey L, Tischer S (2016) Osteoporosis in the adult solid organ transplant population: underlying mechanisms and available treatment options. Osteoporos Int 27(4):1425-1440

30. Woźniak I et al. Influence of polypharmacy on the quality of life in stable kidney transplant recipients. In Transplantation proceedings; 2018. Elsevier.

31. Inderjeeth CA et al (2015) Long-term efficacy, safety, and patient acceptability of ibandronate in the treatment of postmenopausal osteoporosis. Int J Women's Health 7:7

32. Dave $V$ et al (2015) Hypocalcemia post denosumab in patients with chronic kidney disease stage 4-5. Am J Nephrol 41(2):129-137

33. Nissenson AR, Fine RE. Handbook of Dialysis Therapy E-Book. 2016: Elsevier Health Sciences.

\section{Publisher's Note}

Springer Nature remains neutral with regard to jurisdictional claims in published maps and institutional affiliations. 